Research Paper

\title{
Polymorphisms in mitotic checkpoint-related genes can influence survival outcomes of early-stage non-small cell lung cancer
}

\author{
Hyo Gyoung Kang ${ }^{1,2, *}$, Seung Soo Yoo ${ }^{3, *}$, Jin Eun Choi ${ }^{1,2}$, Mi Jeong Hong ${ }^{1,2}$, Sook \\ Kyung Do ${ }^{1,4}$, Cheng Cheng Jin ${ }^{1}$, Soyoun Kim ${ }^{1}$, Won Kee Lee ${ }^{5}$, Sun Ha Choi ${ }^{3}$, So Yeon \\ Lee $^{3}$, Hyun Jung Kim³, Shin Yup Lee ${ }^{3}$, Jaehee Lee ${ }^{3}$, Seung Ick Cha ${ }^{3}$, Chang Ho Kim³, \\ Yangki Seok ${ }^{6}$, Eungbae Lee ${ }^{6}$, Sukki Cho ${ }^{7}$, Sanghoon Jheon' and Jae Yong Park ${ }^{1,2,3,4}$ \\ ${ }^{1}$ Department of Biochemistry and Cell Biology, School of Medicine, Kyungpook National University, Daegu, Republic of Korea \\ ${ }^{2}$ Department of Cell and Matrix Research Institute, School of Medicine, Kyungpook National University, Daegu, Republic of Korea \\ ${ }^{3}$ Department of Internal Medicine, School of Medicine, Kyungpook National University, Daegu, Republic of Korea \\ ${ }^{4}$ BK21 Plus KNU Biomedical Convergence Program, Department of Biomedical Science, Kyungpook National University, \\ Daegu, Republic of Korea \\ ${ }^{5}$ Department of Preventive Medicine, School of Medicine, Kyungpook National University, Daegu, Republic of Korea \\ ${ }^{6}$ Department of Thoracic Surgery, School of Medicine, Kyungpook National University, Daegu, Republic of Korea \\ ${ }^{7}$ Department of Thoracic and Cardiovascular Surgery, School of Medicine, Seoul National University, Seoul, Republic of Korea \\ *These authors have contributed equally to this paper \\ Correspondence to: Jae Yong Park, email: jaeyong@knu.ac.kr \\ Keywords: polymorphisms, mitosis, mitotic checkpoint, survival outcome, lung cancer \\ Received: December 02, $2016 \quad$ Accepted: May 22, $2017 \quad$ Published: June 27, 2017 \\ Copyright: Kang et al. This is an open-access article distributed under the terms of the Creative Commons Attribution License 3.0 \\ (CC BY 3.0), which permits unrestricted use, distribution, and reproduction in any medium, provided the original author and source \\ are credited.
}

\section{ABSTRACT}

This study was conducted to investigate the association between variants in mitotic checkpoint-related genes and clinical outcomes of non-small cell lung cancer (NSCLC). A total of 766 patients with NSCLC who underwent curative surgery were enrolled. Among the 73 variants evaluated, 4 variants were related with survival outcomes. BUB3 rs7897156C $>$ T was associated with worse overall survival under a recessive model (adjusted hazard ratio $=1.58,95 \%$ confidence interval $=1.07-2.33$, $P=0.02$ ). AURKB rs1059476G $>$ A was associated with better overall survival under a recessive model (adjusted hazard ratio $=0.64,95 \%$ confidence interval $=0.41-$ $0.99, P=0.05)$. PTTG1 rs1895320T $>C$ and $R A D 21$ rs1374297C $>$ G were associated with worse disease-free survival. In the functional study, relative luciferase activity was higher at the BUB3 rs7897156T allele compared to that at the C allele. Western blot showed that the phosphorylation of AKT and mTOR in the AURKB variant-type $\left(M^{298}\right)$ was significantly lower than in the AURKB wild-type $\left(T^{298}\right)$. We found that 4 variants of mitotic checkpoint-related genes were associated with survival outcomes in patients with surgically resected NSCLC. Particularly, our results suggest that BUB3 rs7897156C $>$ T and $A U R K B$ rs1059476G $>A$ are functional variants.

\section{INTRODUCTION}

Accurate segregation of chromosomes during mitosis is important to the survival of human cells. Errors in mitosis result in cells with an abnormal number of chromosomes, known as aneuploidy, which can lead to cell-cycle arrest, cell death, or tumorigenesis $[1,2]$. Whether aneuploidy is a cause or consequence of cancer remains controversial; aneuploidy has been detected in most solid tumors, including lung cancer 
[2-4]. Chromosome instability, defined as a high rate of either gain or loss of whole chromosomes and causing aneuploidy, is also one of the hallmarks of human solid tumors $[2,5]$.

During mitosis, there are various checkpoints to ensure the fidelity of chromosome segregation. Checkpoint with FHA and RING finger domains (CHFR) and spindle assembly are examples of mitotic checkpoints [6, 7]. A number of genes, such as mitotic arrest deficient (MAD) $1-3$ and budding uninhibited by benzimidazole (BUB) $1-3$, are also related to mitotic checkpoints to guarantee accurate chromosome segregation [8-11]. Defects in mitotic checkpoints can cause chromosome instability, which contributes to tumorigenesis. $[12,13]$.

Mutations in mitotic checkpoint-related genes such as BUB1 and MADIL1 have been reported in various human cancers, including lung cancer [14-17]. We hypothesized that mutations in mitotic checkpointrelated genes affect not only tumorigenesis, but also the clinical outcomes of cancers. Therefore, we evaluated the association between potentially functional single nucleotide polymorphisms (SNPs) in mitotic checkpointrelated genes and the clinical outcomes of early-stage of non-small cell lung cancers (NSCLC).

\section{RESULTS}

\section{Patient characteristics and clinical predictors}

The clinical and pathological characteristics of patients and their association with overall survival (OS) and disease-free survival (DFS) are shown in Table 1. Pathological stage was significantly associated with both OS and DFS in univariate analysis (log-rank $P=9 \times 10^{-}$ ${ }^{13}$ and $4 \times 10^{-18}$, respectively). Age, gender, and smoking status were also associated with OS (log-rank $P=0.01,7$ $\times 10^{-4}$ and $8 \times 10^{-4}$, respectively).

\section{Association between SNPs and survival outcomes}

The 73 SNPs evaluated and results of multivariate analyses are shown in Supplementary Table 1. Among the 73 SNPs examined, 4 SNPs (rs7897156, rs1059476, rs1895320, and rs1374297) were associated with survival outcomes. BUB3 rs7897156C $>$ T was associated with worse overall survival under a recessive model (CC+CT $(88.2 \%)$ vs. TT (11.8\%), adjusted hazard ratio $[\mathrm{aHR}]=1.58,95 \%$ confidence interval $[\mathrm{CI}]=1.07-$ 2.33, $P=0.02$; Table 2 and Figure 1). Aurora kinase B (AURKB) rs1059476G $>$ A was associated with better overall survival under a recessive model $(\mathrm{GG}+\mathrm{GA}(84.6 \%)$ vs. AA (15.4\%), aHR $=0.64,95 \% \mathrm{CI}=0.41-0.99, P=$ 0.05 ; Table 2 and Figure 1). Although significant $P$ values were not reached, the same trends as OS were observed in DFS for BUB3 rs7897156 and AURKB rs1059476 (Table 2). Pituitary tumor-transforming 1 (PTTG1) rs 1895320 and
RAD21 cohesin complex component (RAD21) rs1374297 were associated with worse DFS (under a recessive model, $\mathrm{TT}+\mathrm{TC}(97.6 \%)$ vs. CC $(2.4 \%), \mathrm{aHR}=2.46,95 \% \mathrm{CI}=$ $1.43-4.23, P=0.001$ and under a codominant model, $\mathrm{CC}$ (34.8\%) vs. CG (48.0\%) vs. GG (17.2\%), aHR = 1.18, $95 \% \mathrm{CI}=1.01-1.38, P=0.04$, respectively; Table 2 and Figure 1). There was no association between 4 SNPs and EGFR, ALK, and RET (Supplementary Table 2).

\section{Effect of rs7897156C $>\mathrm{T}$ on promoter activity of BUB3}

rs $7897156 \mathrm{C}>\mathrm{T}$ is located at the $5^{\prime}$ untranslated region of $B U B 3$ and can change the promoter activity of $B U B 3$. We investigated the effect of $\mathrm{rs} 7897156 \mathrm{C}>\mathrm{T}$ on the promoter activity of $B U B 3$ using a luciferase assay in the H1299 and A549 NSCLC cell lines. The rs7897156T allele showed significantly higher luciferase activity of the $B U B 3$ promoter compared to the $7897156 \mathrm{C}$ allele in both cell lines $(P=0.02$ and 0.003 , respectively; Figure 2A).

\section{Effect of rs7897156C $>$ T on $B U B 3$ mRNA expression}

Increased $B U B 3$ expression was observed in tumor tissues compared to in paired non-malignant lung tissues $(P$ $=2.8 \times 10^{-8}$; Figure $\left.2 \mathrm{~B}\right)$. To identify the functional effect of $B U B 3$ rs $7897156 \mathrm{C}>\mathrm{T}$, we evaluated the mRNA expression according to the rs7897156 genotypes. BUB3 mRNA expression was higher for the rs7897156CT or TT genotypes $(56.8 \%)$ than for the rs7897156CC genotype (43.2\%) in nonmalignant lung tissues $(P=0.04$; Figure $2 \mathrm{C})$.

\section{Functional prediction of $A U R K B$ rs1059476G $>A$}

$A U R K B$ rs $1059476 \mathrm{G}>\mathrm{A}$ is a non-synonymous SNP. Changing the rs1059476G-to-A results in an amino acid change of threonine to methionine at codon 298. We evaluated whether this amino acid change affects protein function using DelPhi calculation and Pymol (http://pymol. org). As shown in Figure 3, the Thr-to-Met change at codon 298 provides increased hydrophobicity of Aurora kinases B.

\section{In vitro effect of $\mathrm{rs} 1059476 \mathrm{G}>\mathrm{A}$}

To assess the functional importance of $A U R K B$ variant-type $\left(\mathrm{M}^{298}\right)$ identified in this study, the effect of the variant-type $\left(\mathrm{M}^{298}\right)$ on AURKB was investigated in vitro. DDK-tagged wild-type $\left(\mathrm{T}^{298}\right)$ and variant-type $\left(\mathrm{M}^{298}\right)$ were transfected into 293T cells. Western blot for the phosphorylation of AKT and mTOR in the variant-type $\left(\mathrm{M}^{298}\right)$ was significantly lower compared with that in the wild-type $\left(\mathrm{T}^{298}\right)$ (Figure 3C). Total protein level of AKT and mTOR was not changed. These findings suggest that $A U R K B$ variant-type $\left(\mathrm{M}^{298}\right)$ decreases the phosphorylation of AKT and mTOR. 
Table 1: Univariate analysis for overall survival and disease-free survival by clinicopathologic features

\begin{tabular}{|c|c|c|c|c|c|c|c|}
\hline \multirow[b]{2}{*}{ Variables } & \multirow[b]{2}{*}{$\begin{array}{c}\text { No. of } \\
\text { cases }\end{array}$} & \multicolumn{3}{|c|}{ Overall survival } & \multicolumn{3}{|c|}{ Disease-free survival } \\
\hline & & $\begin{array}{c}\text { No. of } \\
\text { death } \\
(\%)^{a}\end{array}$ & $\begin{array}{c}\text { 5Y-OSR } \\
(\%)^{\mathrm{b}}\end{array}$ & $\begin{array}{c}\text { Log-Rank } \\
P\end{array}$ & $\begin{array}{c}\text { No. of } \\
\text { event } \\
(\%)^{a}\end{array}$ & $\begin{array}{c}\text { 5Y-DFSR } \\
(\%)^{b}\end{array}$ & $\begin{array}{c}\text { Log-Rank } \\
P\end{array}$ \\
\hline Overall & 766 & $214(27.9)$ & 61 & & $337(44.0)$ & 44 & \\
\hline \multicolumn{8}{|c|}{ Age (years) } \\
\hline$<65$ & 375 & $94(25.1)$ & 66 & 0.01 & $160(42.7)$ & 48 & 0.14 \\
\hline$\geq 65$ & 391 & $120(30.7)$ & 55 & & $177(45.3)$ & 40 & \\
\hline \multicolumn{8}{|l|}{ Gender } \\
\hline Male & 560 & 177 (31.6) & 58 & $7 \times 10^{-4}$ & $260(46.4)$ & 42 & 0.09 \\
\hline Female & 206 & $37(18.0)$ & 71 & & $77(37.4)$ & 53 & \\
\hline \multicolumn{8}{|c|}{ Smoking status } \\
\hline Never & 229 & $43(18.8)$ & 73 & $8 \times 10^{-4}$ & 89 (38.9) & 50 & 0.12 \\
\hline Ever & 537 & $171(31.8)$ & 56 & & $248(46.2)$ & 42 & \\
\hline \multicolumn{8}{|c|}{ Pack-years ${ }^{c}$} \\
\hline$<40$ & 250 & $72(28.8)$ & 57 & 0.27 & $111(44.4)$ & 42 & 0.79 \\
\hline$\geq 40$ & 287 & $99(34.5)$ & 55 & & $137(47.7)$ & 42 & \\
\hline \multicolumn{8}{|c|}{ Histological type } \\
\hline $\mathrm{SCC}$ & 344 & $108(31.4)$ & 59 & 0.30 & $151(43.9)$ & 46 & 0.35 \\
\hline $\mathrm{AC}$ & 405 & $100(24.7)$ & 63 & & $176(43.5)$ & 43 & \\
\hline LCC & 17 & $6(35.3)$ & 61 & & $10(58.8)$ & 39 & \\
\hline \multicolumn{8}{|c|}{ Pathologic stage } \\
\hline I & 363 & $57(15.7)$ & 76 & $9 \times 10^{-13}$ & $102(28.1)$ & 61 & $4 \times 10^{-18}$ \\
\hline II-IIIA & 403 & $157(39.0)$ & 48 & & $235(58.3)$ & 30 & \\
\hline \multicolumn{8}{|c|}{ Adjuvant therapy ${ }^{\mathrm{d}}$} \\
\hline No & 182 & $75(41.7)$ & 47 & 0.71 & $104(57.8)$ & 35 & 0.51 \\
\hline Yes & 221 & $88(36.8)$ & 49 & & $131(58.7)$ & 25 & \\
\hline
\end{tabular}

SCC, squamous cell carcinoma; AC, adenocarcinoma; LCC, large cell carcinoma.

aRow percentage.

${ }^{b}$ Five year-overall survival rate (5Y-OSR) and 5 year-disease free survival rate (5Y-DFSR), proportion of survival derived from Kaplan-Meier analysis.

'In ever-smokers.

${ }^{\mathrm{d} I n}$ pathologic stage II + IIIA: 184 cases received paclitaxel- cisplatin chemotherapy, 11 cases received radiotherapy, and 26 cases received chemotherapy and radiotherapy.

\section{DISCUSSION}

In the present study, we evaluated the effect of 73 SNPs in 25 mitotic-checkpoint related genes on the survival outcomes in patients with surgically resected NSCLC. We found that 4 SNPs (rs7897156, rs1059476, rs1895320, and rs1374297) were associated with OS or DFS.

BUB3 is a mitotic checkpoint protein that is essential for the establishment of correct kinetochore- microtubule attachments [18]. BUB3, in complex with BUB1, delays the onset of anaphase until all mitotic chromosomes are properly attached to the mitotic spindle $[8,19]$. Overexpression of BUB3 was reported in several cancers such as breast and gastric cancer $[20,21]$. In this study, $B U B 3$ mRNA expression was higher in lung tumor tissues than in non-malignant lung tissues. Up-regulation of mitotic checkpoint gene expression is frequently observed in tumors, but the reason remains unclear. 
Table 2: Overall survival and disease-free survival according to genotypes in patients with non-small lung cancer

\begin{tabular}{|c|c|c|c|c|c|c|c|c|c|c|c|c|}
\hline \multirow[b]{2}{*}{ Gene/SNP } & \multirow[b]{2}{*}{ Genotype $^{e}$} & \multirow[b]{2}{*}{$\begin{array}{c}\text { No. of } \\
\text { cases }(\%)^{\mathrm{a}}\end{array}$} & \multicolumn{5}{|c|}{ Overall survival } & \multicolumn{5}{|c|}{ Disease-free survival } \\
\hline & & & $\begin{array}{c}\text { No. of } \\
\text { deaths }(\%)^{b}\end{array}$ & $\begin{array}{c}\text { 5Y-OSR } \\
(\%)^{\mathrm{c}}\end{array}$ & $\begin{array}{c}\text { Log- } \\
\operatorname{rank} P\end{array}$ & $\operatorname{HR}(95 \% \mathrm{CI})^{\mathrm{c}}$ & $P^{\mathrm{d}}$ & $\begin{array}{c}\text { No. of } \\
\text { events }(\%)^{b}\end{array}$ & $\begin{array}{c}\text { 5Y-DFSR } \\
(\%)^{\mathrm{c}}\end{array}$ & $\begin{array}{c}\text { Log- } \\
\operatorname{rank} P\end{array}$ & $\operatorname{HR}(95 \% \mathrm{CI})^{\mathrm{c}}$ & $P^{d}$ \\
\hline$B U B 3$ & $\mathrm{CC}$ & $325(43.2)$ & $88(27.1)$ & 61 & 0.08 & 1.00 & & $144(44.3)$ & 42 & 0.57 & 1.00 & \\
\hline \multirow[t]{5}{*}{ rs7897156 } & CT & $339(45.0)$ & $90(26.6)$ & 67 & & $1.04(0.77-1.39)$ & 0.81 & $144(42.5)$ & 50 & & $0.97(0.77-1.22)$ & 0.77 \\
\hline & TT & $89(11.8)$ & $31(34.8)$ & 38 & & $1.61(1.06-2.44)$ & 0.03 & $39(43.8)$ & 34 & & $1.25(0.87-1.79)$ & 0.23 \\
\hline & Dominant & & & & 0.54 & $1.14(0.86-1.50)$ & 0.36 & & & 0.71 & $1.01(0.81-1.26)$ & 0.90 \\
\hline & Recessive & & & & 0.02 & $1.58(1.07-2.33)$ & 0.02 & & & 0.40 & $1.27(0.91-1.78)$ & 0.17 \\
\hline & Codominant & & & & & $1.20(0.98-1.47)$ & 0.08 & & & & $1.07(0.90-1.26)$ & 0.47 \\
\hline$A U R K B$ & GG & $259(34.4)$ & $75(29.0)$ & 54 & 0.07 & 1.00 & & $118(45.6)$ & 40 & 0.09 & 1.00 & \\
\hline \multirow[t]{5}{*}{ rs1059476 } & GA & $378(50.2)$ & $109(28.8)$ & 62 & & $0.93(0.69-1.25)$ & 0.62 & $169(44.7)$ & 45 & & $0.89(0.70-1.12)$ & 0.32 \\
\hline & $\mathrm{AA}$ & $116(15.4)$ & $22(19.0)$ & 75 & & $0.61(0.38-0.98)$ & 0.04 & $40(34.5)$ & 55 & & $0.71(0.50-1.02)$ & 0.06 \\
\hline & Dominant & & & & 0.21 & $0.85(0.64-1.13)$ & 0.27 & & & 0.15 & $0.85(0.67-1.06)$ & 0.15 \\
\hline & Recessive & & & & 0.03 & $0.64(0.41-0.99)$ & 0.05 & & & 0.05 & $0.76(0.55-1.07)$ & 0.11 \\
\hline & Codominant & & & & & $0.82(0.67-1.01)$ & 0.07 & & & & $0.86(0.73-1.01)$ & 0.06 \\
\hline PTTG1 & TT & $520(69.8)$ & $148(28.5)$ & 60 & 0.05 & 1.00 & & $214(41.2)$ & 47 & 0.001 & 1.00 & \\
\hline \multirow[t]{5}{*}{ rs 1895320} & $\mathrm{TC}$ & $207(27.8)$ & $49(23.7)$ & 67 & & $0.74(0.53-1.03)$ & 0.07 & $93(44.9)$ & 44 & & $1.01(0.79-1.29)$ & 0.94 \\
\hline & $\mathrm{CC}$ & $18(2.4)$ & $9(50.0)$ & 48 & & $1.52(0.77-2.99)$ & 0.23 & $14(77.8)$ & 10 & & $2.47(1.42-4.27)$ & 0.001 \\
\hline & Dominant & & & & 0.31 & $0.80(0.59-1.09)$ & 0.16 & & & 0.17 & $1.10(0.87-1.39)$ & 0.45 \\
\hline & Recessive & & & & 0.05 & $1.65(0.84-3.23)$ & 0.14 & & & 0.0001 & $2.46(1.43-4.23)$ & 0.001 \\
\hline & Codominant & & & & & $0.90(0.69-1.18)$ & 0.44 & & & & $1.18(0.96-1.46)$ & 0.11 \\
\hline$R A D 21$ & $\mathrm{CC}$ & $260(34.8)$ & $69(26.5)$ & 62 & 0.59 & 1.00 & & $104(40.0)$ & 50 & 0.18 & 1.00 & \\
\hline \multirow[t]{5}{*}{ rs1374297 } & CG & $358(48.0)$ & $99(27.7)$ & 62 & & $1.06(0.78-1.45)$ & 0.70 & 157 (43.9) & 44 & & $1.12(0.87-1.43)$ & 0.39 \\
\hline & GG & $128(17.2)$ & $38(29.7)$ & 57 & & $1.26(0.85-1.88)$ & 0.26 & $62(48.4)$ & 37 & & $1.41(1.03-1.94)$ & 0.03 \\
\hline & Dominant & & & & 0.59 & $1.11(0.83-1.49)$ & 0.48 & & & 0.18 & $1.19(0.94-1.50)$ & 0.16 \\
\hline & Recessive & & & & 0.32 & $1.22(0.85-1.73)$ & 0.28 & & & 0.10 & $1.32(1.00-1.75)$ & 0.05 \\
\hline & Codominant & & & & & $1.11(0.91-1.36)$ & 0.29 & & & & $1.18(1.01-1.38)$ & 0.04 \\
\hline
\end{tabular}

${ }^{a}$ Column percentage.

${ }^{\mathrm{b}}$ Row percentage.

${ }^{c}$ Five year-overall survival rate (5Y-OSR) and 5 year-disease free survival rate (5Y-DFSR), proportion of survival derived from Kaplan-Meier analysis.

${ }^{\mathrm{d}}$ Hazard ratios (HRs), 95\% confidence intervals (CIs) and corresponding $P$-values were calculated using multivariate Cox proportional hazard models, adjusted for age, sex,

smoking status, tumor histology, pathologic stage and adjuvant therapy.

${ }^{\mathrm{e}}$ Genotype failure: 13 cases for the rs 7897156,13 cases for the rs 1059476,21 cases for the rs 1895320 , and 20 cases for the rs 1374297.

Overexpression of mitotic checkpoint genes may occur because of compensatory mechanisms for other defects in mitotic checkpoint function. Alternatively, overexpression of mitotic checkpoint genes may result in defective mitotic checkpoint function [22].

Associations between the overexpression of mitotic checkpoint genes and poor prognosis have been reported in several cancers [23-27]. In the present study, a higher level of $B U B 3$ expression was observed in lung tumor, and worse OS in patients with the $B U B 3$ rs7897156TT genotype was observed. Our finding is biologically plausible given the putative function of the SNP. In the in vitro luciferase assay, the rs $7897156 \mathrm{C}$-to- $\mathrm{T}$ change increased the activity of the $B U B 3$ promoter. In addition, the rs7897156CT or TT genotypes showed significantly higher $B U B 3$ mRNA expression than the rs7897156CC genotype. These results suggest that $B U B 3$ rs $7897156 \mathrm{C}>\mathrm{T}$ is a functional SNP. Therefore, the rs7897156C-to-T change may have resulted in overexpression of $B U B 3$ and may affect mitotic checkpoint function to influence the prognosis of patients with NSCLC. To the best of our knowledge, this is the first study to show that $B U B 3$ rs $7897156 \mathrm{C}>\mathrm{T}$ is a functional SNP and can affect prognosis of NSCLC.

The family of Aurora kinases (A, B, and C) act as key regulators of mitotic cell division by regulating the functions of centrosomes, bipolar spindle assembly, and chromosome segregation [28]. Up-regulation of Aurora kinases has been reported in various human cancers, and therapeutic inhibition of these kinases are actively 
A. $B U B 3 \mathrm{rs} 7897156 \mathrm{C}>\mathrm{T}$
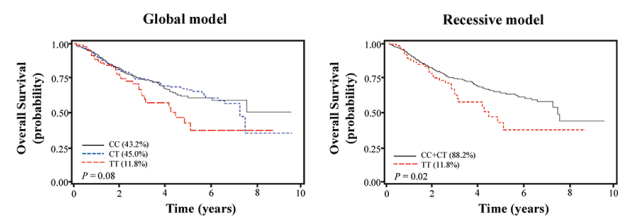

C. $P T T G 1$ rs $1895320 \mathrm{~T}>\mathrm{C}$
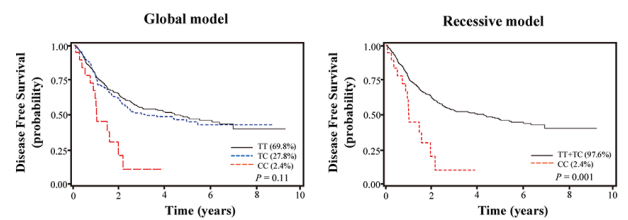

B. $A U R K B$ rs $1059476 \mathrm{G}>\mathrm{A}$
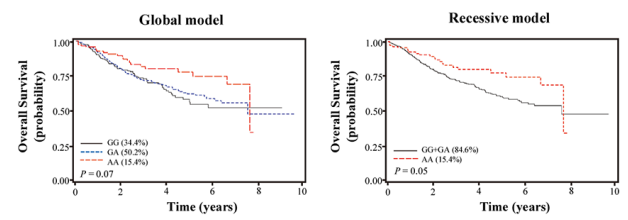

D. $R A D 21$ rs1374297C $>\mathrm{G}$
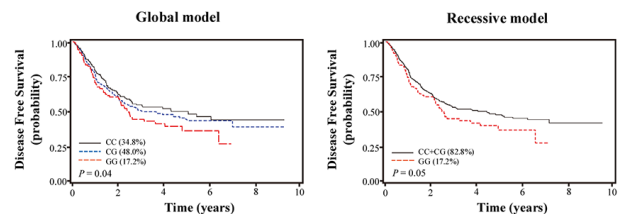

Figure 1: Kaplan-Meier plots of overall survival or disease-free survival according to (A) $B U B 3$ rs $7897156 \mathrm{C}>\mathrm{T}$, (B) $A U R K B$ rs1059476G $>$ A, (C) $P T T G 1$ rs1895320T $>$ C, and (D) $R A D 21$ rs1374297C $>$ G genotypes. $P$ values, multivariate Cox proportional hazard model.

A.
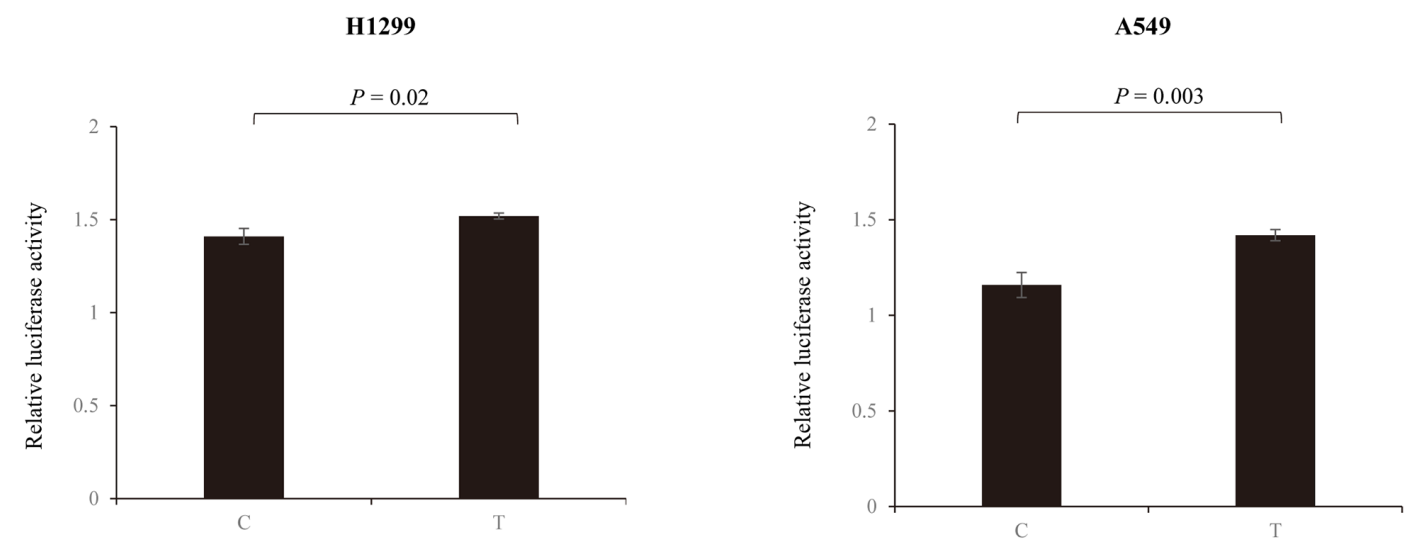

B.

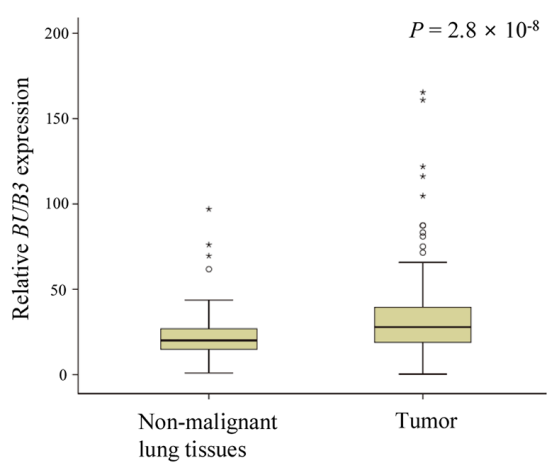

C.

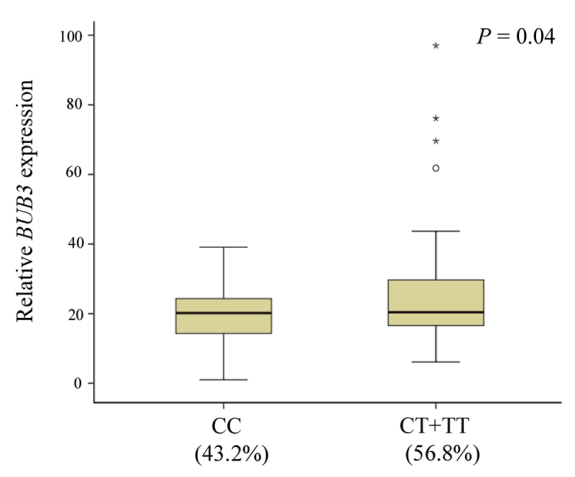

Figure 2: Effect of $\boldsymbol{B U B} 3$ rs7897156C $>$ T. (A) Functional analysis of $B U B 3$ rs $7897156 \mathrm{C}>\mathrm{T}$ by luciferase reporter assay. Transcription activity of rs 7897156C $>$ T was measured using a Dual-Luciferase Reporter Assay System in the H1299 and A549 cell lines. Firefly luciferase activity was normalized to Renilla luciferase activity. (B) mRNA expression levels of $B U B 3$ in tumor and non-malignant lung tissues. (C) $B U B 3$ mRNA expression by the rs $7897156 \mathrm{C}>\mathrm{T}$ genotypes in non-malignant lung tissues. The BUB3 mRNA expression levels and association with the rs7897156C $>$ T genotypes were examined in 114 cases with tumor and paired non-malignant lung tissues. The mRNA expression level of $B U B 3$ was normalized to that of the $\beta$-actin gene. $P$ values, Student's $t$-test. 
researched as anti-mitotic therapies for cancers [9, 28]. In this study, patients with the $A U R K B$ rs $1059476 \mathrm{AA}$ genotype showed better OS than those with the $A U R K B$ rs1059476GA or GG genotypes. The rs1059476G $>\mathrm{A}$ is located in exon of $A U R K B$ and a non-synonymous SNP. The rs1059476G-to-A change results in the replacement of threonine to methionine at codon 298. The prediction of the three-dimensional model using DelPhi calculation and Pymol program showed increased hydrophobicity of Aurora kinases B by the amino acid change of T298M. Western blot for the phosphorylation of AKT and mTOR was decreased in $A U R K B$ the variant-type $\left(\mathrm{M}^{298}\right)$ compared to $A U R K B$ the wild-type $\left(\mathrm{T}^{298}\right)$. However, the biological mechanism between the $A U R K B$ rs1059476G $>A$ and survival outcomes remains unclear. Further studies are needed to clarify the role of $A U R K B$ rs $1059476 \mathrm{G}>\mathrm{A}$ in cancer.

In the present study, PTTG1 rs1895320T $>\mathrm{C}$ and $R A D 21$ rs1374297C $>\mathrm{G}$ were associated with worse DFS. The PTTG1 encodes securin, which inhibits the sisterchromatids from separating until late anaphase [29].
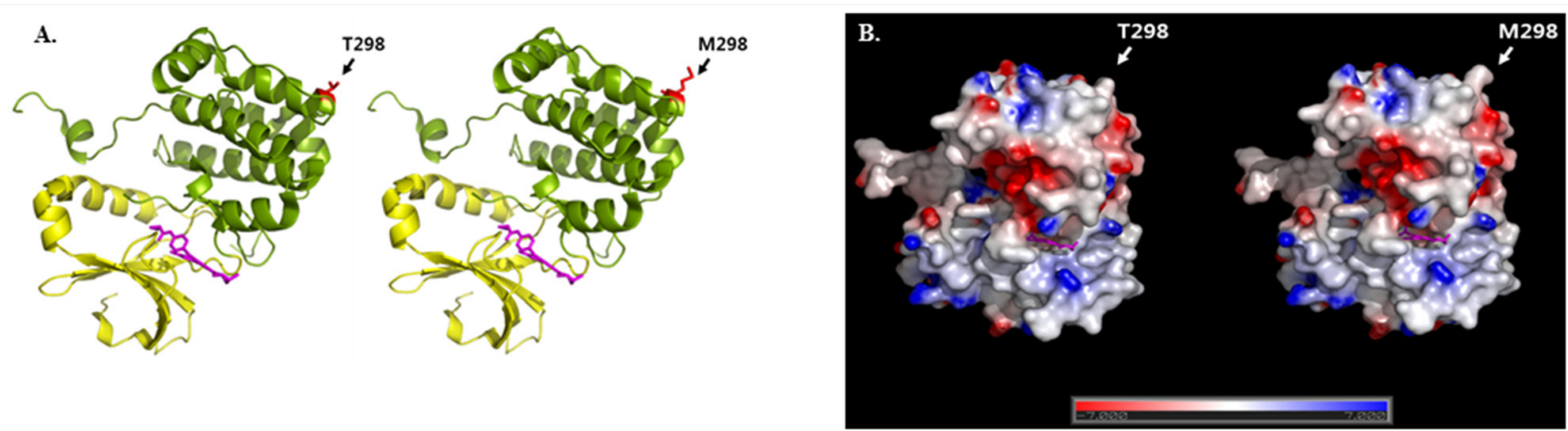

Overexpression of PTTG1 and its relationship with poor prognosis were observed in hepatocellular carcinoma and adrenocortical cancer [27, 30]. Li et al. [31] reported that overexpression of PTTG1 was associated with lymph node and distant metastases in NSCLC and was correlated with poor OS. RAD21 is a component of the cohesion complex and is involved in chromosome segregation during mitosis, DNA repair, and apoptosis [32]. Enhanced RAD21 expression was associated with early relapse and poor prognosis of breast cancer and KRAS mutant colorectal cancer $[32,33]$. An association between high expression of $R A D 21$ and cisplatin resistance was reported in NSCLC [34].

In summary, we found that 4 SNPs (rs7897156, rs1059476, rs1895320, and rs1374297) in mitoticcheckpoint related genes were associated with survival outcomes of NSCLC. In addition, functional data suggest that $B U B 3$ rs $7897156 \mathrm{C}>\mathrm{T}$ and $A U R K B$ rs $1059476 \mathrm{G}>\mathrm{A}$ are functional SNPs. Additional studies are required to confirm the effect of these SNPs in diverse ethnic groups.

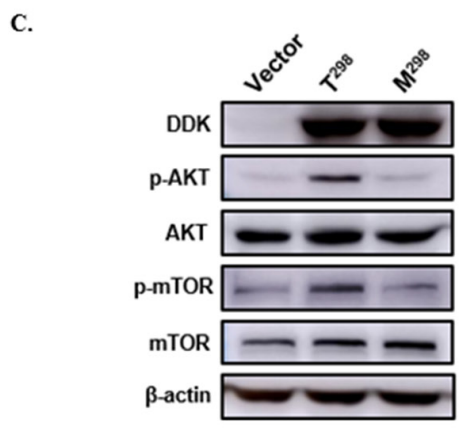

Figure 3: Effect of $\boldsymbol{A U R K B}$ rs1059476G $>$ A. (A) Structure model of Aurora kinase (PDB ID: 4AF3) wild-type (T298) and variant type (M298). Kinase domain (yellow) and substrate selective region (green) are shown with kinase inhibitor, VX680 (magenta). Single nucleotide polymorphism residue is highlighted in red. (B) The surface electrostatic potential of wild-type and variant-type was calculated using DelPhi calculation; all figures were constructed using Pymol (http://pymol.org). (C) Western blot of DDK-tagged AURKB wild-type $\left(\mathrm{T}^{298}\right)$ and variant-type $\left(\mathrm{M}^{298}\right)$, for phosphorylated AKT (p-AKT), total AKT, phosphorylated mTOR (p-mTOR), and total mTOR, which were transfected into $293 \mathrm{~T}$ cells. $\beta$-actin was used as internal control. 


\section{MATERIALS AND METHODS}

\section{Study populations}

In this study, 766 patients with pathologic stage I, II, and IIIA (micro-invasive N2) NSCLC were enrolled. All patients underwent surgery with curative intent at the Kyungpook National University Hospital, Daegu, Korea $(\mathrm{n}=338)$ or Seoul National University Bundang Hospital, Bundang, Korea $(n=428)$. Written informed consent was obtain from all patients before surgery. All patients in this study were of Korean ethnicity. This study was approved by the Institutional Review Boards of the Kyungpook National University Hospital and Seoul National University Bundang Hospital.

\section{SNP selection and genotyping}

By searching published review articles, 32 mitotic checkpoint-related genes were selected $[8-10,35,36]$. Using HapMap database, 2035 SNPs in 32 mitotic checkpoint-related genes were collected. Among the 2035 SNPs, 968 SNPs were excluded because the minor allele frequency was $<0.05$ in the HapMap JPT data. To identify potentially functional SNPs, the FuncPred in the SNP info web server (http://snpinfo.niehs.nih.gov) was used and 116 potentially functional SNPs were selected from the remaining 1067 SNPs. Among these, 43 SNPs were excluded because of linkage disequilibrium $\left(r^{2}>\right.$ 0.8 ), based on HaploView (http://broad.mit.edu/mpg/ haploview). A total of 73 SNPs in 25 mitotic checkpointrelated genes were genotyped by the MassARRAY ${ }^{\circledR}$ iPLEX assay (SEQUENOM Inc., San Diego, CA, USA). Approximately $5 \%$ of the samples were randomly selected to be genotyped again by a different investigator, by a restriction fragment length polymorphism assay, and the results were $100 \%$ concordant.

\section{Promoter-luciferase constructs and luciferase assay}

We investigated whether $B U B 3$ rs7897156C $>\mathrm{T}$ modulates the activity of the $B U B 3$ gene promoter in a luciferase assay. Promoter fragments of $B U B 3$, including rs7897156, were synthesized by PCR using the following primers: $B U B 3$ forward, 5'-GGGGTAC CCCGTAGTTTCCACGCGTCCAGC-3'; BUB3 rev erse, 5'-CCGCTCGAGCGG GAAACGGGATCCCCTGC GAA-3'. The PCR products were cloned into the KpnI/ XhoI site of the pGL3-basic plasmid (Promega, Madison, WI, USA). The correct sequences of all clones were verified by DNA sequencing. The NSCLC cell lines H1299 and A549 were transfected with each reported construct and pRL-SV40 vector (Promega), using Effectene transfection reagent (Qiagen, Hilden, Germany). The cells were collected 48 hour after transfection. Luciferase activity was measured using the Dual-Luciferase ${ }^{\circledR}$ Reporter Assay System (Promega) and the results were normalized based on the activity of Renilla luciferase. All experiments were performed in triplicate.

\section{RNA preparation and quantitative reverse transcription-PCR (qRT-PCR)}

BUB3 mRNA expression was examined by qRT-PCR. Total RNAs from tumors and paired non-malignant lung tissues $(\mathrm{n}=114)$ were isolated using Trizol (Invitrogen, Carlsbad, USA). Realtime PCR was performed using a LightCycler 480 (Roche Applied Science, Mannheim, Germany) with QuantiFast SYBR Green PCR Master Mix (Qiagen). The real-time PCR primers for BUB3 and $\beta$-actin genes involved the following primers: $B U B 3$ forward, 5'-AGTGTTGGTGTGGGACTTAC-3'; BUB3 reverse, 5'-AATACTCAACTGCCACTCGG-3'; $\beta$-actin forward, 5'-TTGTTACAGGAAGTCCCTTGCC-3'; $\beta$-actin reverse, 5'- ATGCTATCACCTCCCCTGTGT-3'. Each sample was run in duplicate. Relative $B U B 3$ mRNA expression was normalized to that of $\beta$-actin expression and then evaluated using the $2^{-\Delta \Delta C t}$ method [37].

\section{Construction of three-dimensional model for Aurora kinase}

To evaluate the potential effect of $A U R K B$ rs $1059476 \mathrm{G}>\mathrm{A}$, which substitutes threonine with methionine at codon 298, the three-dimensional model of the Aurora kinase (PDB ID: 4AF3) SNP variant type was obtained by in silico substitution of Thr298 by Met without altering the backbone geometry, using Pymol program (http://pymol.org). The surface electrostatic potential was calculated using DelPhi calculation and displayed using Pymol.

\section{Construction of expression plasmids for AURKB wild (T298) and variant-type (M298)}

To examine the potential effect of wild-type (T298) and variant-type (M298) of AURKB, we constructed wild-type and variant-type plasmids. The AURKB (MycDDK-tagged) Human cDNA ORF Clone from Origene Tech (Rockville, MD, USA) was used as a wild-type (T298). The variant-type (M298) construct was created from pCMV6-AURKB-wild-type (T298) using the Quickchange II Site-Directed Mutagenesis kit (Stratagene, Cedar Creek, TX, USA) according to the manufacturer's protocol. The mutagenesis experiment was amplified using 5'- CCC GCT TCC GTG CCC ATG GGA GCC CAG GAC CTC -3' (forward) and 5'- GAG GTC CTG GGC TCC CAT GGG CAC GGA AGC GGG -3' (reverse) primers. Both constructs were verified by sequencing analysis. 


\section{Cell culture and transfection}

The 293T cells were cultured in Dulbecco's modified Eagle's medium supplemented with 10\% heatinactivated fetal bovine serum. Cells were seeded in a six well plate as the cells were approximately $80 \sim 90 \%$ confluent. At the next day, cells were transfected with pCMV6-AURKB-wild-type (T298), pCMV6-AURKBvariant-type (M298), or pCMV6 empty vector using the Lipofectamine 2000 (Invitrogen, Carlsbad, CA, USA) according to the manufacturer's protocol. After two days from transfection, cells were harvested.

\section{Western blot}

Cell proteins were extracted using M-PER Mammalian Protein Extraction Reagent (Thermo Fisher Scientific, Waltham, MA, USA), supplemented with protease inhibitor and phosphatase inhibitor (Sigma, St. Louis, MO, USA). Western blots were prepared by standard procedures using anti-DDK (Origene Tech, Rockville, MD, USA), anti-actin (Santa Cruz, CA, USA), anti-AKT, anti-phospho-AKT, anti-mTOR, and antiphospho-mTOR (Cell signaling Technology, Danvers, MA, USA). Immunoreactivity was detected by an Immunobilon Western Chemiluminescent HRP Substrate (Millipore, Billerica, MA, USA).

\section{Statistical analysis}

OS was measured from the day of surgery to the day of death or last follow-up. DFS was counted between the day of surgery and recurrence or death from any cause. The Kaplan-Meier test was performed to assess OS and DFS according to genotype. The aHR and $95 \% \mathrm{CI}$ were calculated using multivariate Cox proportional hazard models, adjusted for age ( $<65$ years $v s . \geq 65$ years), gender (female $v s$. male), smoking status (never $v s$. ever), histological type (squamous cell carcinoma vs. adenocarcinoma), pathological stage (stage I $v s$. stage II or IIIA), and adjuvant therapy (yes $v s$. no). A $P$ value of less than 0.05 was considered statistically significant. The statistical data were obtained using Statistical Analysis System for Windows, version 9.2 (SAS Institute, Cary, NC, USA).

\section{ACKNOWLEDGMENTS}

This research was supported by the Basic Science Research Program through the National Research Foundation of Korea (NRF) funded by the Ministry of Education (grant number: NRF-2014R1A6A3A01008953), in part by a grant of the Korea Health Technology R\&D Project through the Korea Health Industry Development Institute (KHIDI), funded by the Ministry of Health \& Welfare, Republic of Korea (grant number: HI14C0402).

\section{CONFLICTS OF INTEREST}

The authors declare no conflicts of interest.

\section{REFERENCES}

1. Storchova Z, Kuffer C. The consequences of tetraploidy and aneuploidy. J Cell Sci. 2008; 121: 3859-3866.

2. Gordon DJ, Resio B, Pellman D. Causes and consequences of aneuploidy in cancer. Nat Rev Genet. 2012; 13: 189-203.

3. Mitelman F, Heim S. Chromosome abnormalities in cancer. Cancer Detect Prev. 1990; 14: 527-537.

4. Sen S. Aneuploidy and cancer. Curr Opin Oncol. 2000; 12: 82-88.

5. Geigl JB, Obenauf AC, Schwarzbraun T, Speicher MR. Defining 'chromosomal instability'. Trends Genet. 2008; 24: 64-69.

6. Scolnick DM, Halazonetis TD. Chfr defines a mitotic stress checkpoint that delays entry into metaphase. Nature. 2000; 406: 430-435.

7. Lara-Gonzalez P, Westhorpe FG, Taylor SS. The spindle assembly checkpoint. Curr Biol. 2012; 22: R966-980.

8. Kops GJ, Weaver BA, Cleveland DW. On the road to cancer: aneuploidy and the mitotic checkpoint. Nat Rev Cancer. 2005; 5: 773-785.

9. Jackson JR, Patrick DR, Dar MM, Huang PS. Targeted antimitotic therapies: can we improve on tubulin agents? Nat Rev Cancer. 2007; 7: 107-117.

10. Baker DJ, Chen J, van Deursen JM. The mitotic checkpoint in cancer and aging: what have mice taught us? Curr Opin Cell Biol. 2005; 17: 583-589.

11. Yuen KW, Montpetit B, Hieter P. The kinetochore and cancer: what's the connection? Curr Opin Cell Biol. 2005; 17: 576-582.

12. Dobles M, Liberal V, Scott ML, Benezra R, Sorger PK. Chromosome missegregation and apoptosis in mice lacking the mitotic checkpoint protein Mad2. Cell. 2000; 101: 635-645.

13. Michel LS, Liberal V, Chatterjee A, Kirchwegger R, Pasche B, Gerald W, Dobles M, Sorger PK, Murty VV, Benezra R. MAD2 haplo-insufficiency causes premature anaphase and chromosome instability in mammalian cells. Nature. 2001; 409: 355-359.

14. Cahill DP, Lengauer C, Yu J, Riggins GJ, Willson JK, Markowitz SD, Kinzler KW, Vogelstein B. Mutations of mitotic checkpoint genes in human cancers. Nature. 1998; 392: 300-303.

15. Gemma A, Seike M, Seike Y, Uematsu K, Hibino S, Kurimoto F, Yoshimura A, Shibuya M, Harris CC, Kudoh S. Somatic mutation of the hBUB1 mitotic checkpoint gene in primary lung cancer. Genes Chromosomes Cancer. 2000; 29: $213-218$. 
16. Ohshima K, Haraoka S, Yoshioka S, Hamasaki M, Fujiki T, Suzumiya J, Kawasaki C, Kanda M, Kikuchi M. Mutation analysis of mitotic checkpoint genes (hBUB1 and hBUBR1) and microsatellite instability in adult T-cell leukemia/ lymphoma. Cancer Lett. 2000; 158: 141-150.

17. Tsukasaki K, Miller CW, Greenspun E, Eshaghian S, Kawabata H, Fujimoto T, Tomonaga M, Sawyers C, Said JW, Koeffler HP. Mutations in the mitotic check point gene, MAD1L1, in human cancers. Oncogene. 2001; 20: 3301-3305.

18. Logarinho E, Resende T, Torres C, Bousbaa H. The human spindle assembly checkpoint protein Bub3 is required for the establishment of efficient kinetochore-microtubule attachments. Mol Biol Cell. 2008; 19: 1798-1813.

19. Tang Z, Shu H, Oncel D, Chen S, Yu H. Phosphorylation of Cdc20 by Bub1 provides a catalytic mechanism for APC/C inhibition by the spindle checkpoint. Mol Cell. 2004; 16: 387-397.

20. Yuan B, Xu Y, Woo JH, Wang Y, Bae YK, Yoon DS, Wersto RP, Tully E, Wilsbach K, Gabrielson E. Increased expression of mitotic checkpoint genes in breast cancer cells with chromosomal instability. Clin Cancer Res. 2006; 12: 405-410.

21. Grabsch H, Takeno S, Parsons WJ, Pomjanski N, Boecking A, Gabbert HE, Mueller W. Overexpression of the mitotic checkpoint genes BUB1, BUBR1, and BUB3 in gastric cancer--association with tumour cell proliferation. J Pathol. 2003; 200: 16-22.

22. Warren CD, Brady DM, Johnston RC, Hanna JS, Hardwick KG, Spencer FA. Distinct chromosome segregation roles for spindle checkpoint proteins. Mol Biol Cell. 2002; 13: 3029-3041.

23. Rimkus C, Friederichs J, Rosenberg R, Holzmann B, Siewert JR, Janssen KP. Expression of the mitotic checkpoint gene MAD2L2 has prognostic significance in colon cancer. Int J Cancer. 2007; 120: 207-211.

24. Hernando E, Nahle Z, Juan G, Diaz-Rodriguez E, Alaminos M, Hemann M, Michel L, Mittal V, Gerald W, Benezra R, Lowe SW, Cordon-Cardo C. Rb inactivation promotes genomic instability by uncoupling cell cycle progression from mitotic control. Nature. 2004; 430: 797-802.

25. Portella G, Passaro C, Chieffi P. Aurora B: a new prognostic marker and therapeutic target in cancer. Curr Med Chem. 2011; 18: 482-496.

26. Vischioni B, Oudejans JJ, Vos W, Rodriguez JA, Giaccone G. Frequent overexpression of aurora B kinase, a novel drug target, in non-small cell lung carcinoma patients. Mol Cancer Ther. 2006; 5: 2905-2913.

27. Fujii T, Nomoto S, Koshikawa K, Yatabe Y, Teshigawara O, Mori T, Inoue S, Takeda S, Nakao A. Overexpression of pituitary tumor transforming gene 1 in $\mathrm{HCC}$ is associated with angiogenesis and poor prognosis. Hepatology. 2006; 43: 1267-1275.

28. Katayama H, Brinkley WR, Sen S. The Aurora kinases: role in cell transformation and tumorigenesis. Cancer Metastasis Rev. 2003; 22: 451-464.

29. Marangos P, Carroll J. Securin regulates entry into M-phase by modulating the stability of cyclin B. Nat Cell Biol. 2008; 10: 445-451.

30. Demeure MJ, Coan KE, Grant CS, Komorowski RA, Stephan E, Sinari S, Mount D, Bussey KJ. PTTG1 overexpression in adrenocortical cancer is associated with poor survival and represents a potential therapeutic target. Surgery. 2013; 154: 1405-1416; discussion 1416.

31. Li H, Yin C, Zhang B, Sun Y, Shi L, Liu N, Liang S, Lu S, Liu Y, Zhang J, Li F, Li W, Liu F et al. PTTG1 promotes migration and invasion of human non-small cell lung cancer cells and is modulated by miR-186. Carcinogenesis. 2013; 34: 2145-2155.

32. Xu H, Yan M, Patra J, Natrajan R, Yan Y, Swagemakers S, Tomaszewski JM, Verschoor S, Millar EK, van der Spek P, Reis-Filho JS, Ramsay RG, O'Toole SA et al. Enhanced RAD21 cohesin expression confers poor prognosis and resistance to chemotherapy in high grade luminal, basal and HER2 breast cancers. Breast Cancer Res. 2011; 13: R9.

33. Deb S, Xu H, Tuynman J, George J, Yan Y, Li J, Ward RL, Mortensen N, Hawkins NJ, McKay MJ, Ramsay RG, Fox SB. RAD21 cohesin overexpression is a prognostic and predictive marker exacerbating poor prognosis in KRAS mutant colorectal carcinomas. Br J Cancer. 2014; 110: 1606-1613.

34. Zhao J, Fu W, Liao H, Dai L, Jiang Z, Pan Y, Huang H, Mo Y, Li S, Yang G, Yin J. The regulatory and predictive functions of miR-17 and miR-92 families on cisplatin resistance of non-small cell lung cancer. BMC Cancer. 2015; 15: 731.

35. Clarke DJ, Gimenez-Abian JF. Checkpoints controlling mitosis. Bioessays. 2000; 22: 351-363.

36. Wang X, Dai W. Shugoshin, a guardian for sister chromatid segregation. Exp Cell Res. 2005; 310: 1-9.

37. Livak KJ, Schmittgen TD. Analysis of relative gene expression data using real-time quantitative PCR and the 2(-Delta Delta C(T)) Method. Methods. 2001; 25: 402-408. 